\title{
AN APPROACH TO A CHILD (1 WEEK TO 36 MONTHS) WITH FEVER
}

ABSTRACT

Nearly seventy percent of all children between the ages of one week and two-years-ofage are brought to Kanti Children's Hospital for some type of febrile episode. And $50 \%$ of these visits are for temperatures greater than or equal to 39 degrees celsius. These children may have significant bacterial infection. In $35 \%$ of these children there's no definable source for the fever on clinical examination. So the child that don't have identifiable sources could be either bacteremic, meningitis or could have a bone or joint infection in evolution. Simple clinical observation to differentiate a well looking infant from a toxic infant helps to differentiate children who needs admisson or out patient follow-up.

Key Words: Fever, young infant, antibiotics, management.

\section{INTRODUCTION}

Children are smaller, their surface area is greater in comparing with the body weight therefore they tend to have higher metabolic rates and because of that their core temperatures are higher than that of an adult. So for a child, a rectal temperature of greater than or equal to $38 \mathrm{C}$ degrees, or $104 \mathrm{~F}$ degrees is considered a fever. Anything below that is acceptable as normal. So in children, in the age group 0-36 months, fever documented at home by a reliable adult should be treated the same way as reported by a nurse or a colleague. The Integrated
Management of Childhood Illnesses (IMCI) includes fever even if reported by mother although there may not be fever during examination by a health worker. ${ }^{1}$

The causes of fever could be infective or noninfective. In developing countries infective causes are the primary one and it could be viral or bacterial. The best guide to distinguishing bacterial from viral is clinical acumen. ${ }^{2}$ It is always important to quesition about recent immunizations in this age group because some vaccines tend to give fever. DPT, the pertussis component, can give

1. Institute of Medicine, Maharajgunj, Kathmandu, Nepal.

Address for correspondence : Prof. Dr. Pushpa Raj Sharma

Dept. of Child Health, Institute of Medicine, Maharajgunj

P.O. Box: 2533, Kathmandu, Nepal.

Email: paed7@healthnet.org.np 
a fever 24 hours or so after the vaccine. MMR can cause fever in about $40 \%$ anywhere from 5 to 7 days after the vaccine. It can be as high as $38 \mathrm{C}$ or $39 \mathrm{C}$ degrees. ${ }^{3}$ So if this quesitios is not asked, an infant may get a sepsis work-up.

\section{THE YOUNG INFANT (LESS THAN TWO MONTHS)}

Serious bacterial infections can present with normal or subnormal temperatures. ${ }^{4}$ So an absence of a fever does not rule out a serious bacterial illness in a child. An issue that we are seeing right now, this time of year, is over-bundling. ${ }^{5}$ Even in summer young infants are over-bundled specially in Tarai and their temperature rises significantly. One way to deal with that and try to figure out if that's really a fever or over-bundling is summarized here: unbundle the patient and recheck the temperature 15 to 30 minutes later, prior to giving any type of antipyretic, and see if the child's temperature is down and the patient looks good, then it's probably a fever related to over-bundling. Again, it depends on how the patient is doing and what the history is, but it's one way to look this type of a problem. The response to antipyretics does not predict the presence of bacteremia

\section{FEVER AND SERIOUS BACTERIAL INFECTION}

The prevalence of serious bacterial infections in infants less than or equal to 2 months of age who come in with fevers of $39 \mathrm{C}$ degrees or greater is high. ${ }^{6}$ We are defining serious bacterial infections as these: meningitis, sepsis, bone and joint infections, urinary tract infections, pneumonia and enterocolitis. Otitis media except in young infants and sinusitis are not listed as serious bacterial infection because they are not considered serious bacterial infections. ${ }^{7}$

The bacterial pathogen in this age group are B beta streptococcus, E. coli, Listeria monocytogenes occasionally, staphylococcus, streptococcus, staphylococcus species and primarily staphylococcus aureus. Streptococcus pneumoniae and Hemophilus influenzae are starting to be seen more frequently. ${ }^{8}$ We've actually seen a few cases of children who've had strep pneumoniae sepsis as a neonate. So neonatal sepsis due to strep pneumoniae probably has to do with inadequate antibodies transferred from the mother to the baby. The same thing with Hemophilus influenzae. In developed countries Hemophilus influenzae type $\mathrm{B}$ disease are not seen commonly in children greater than two or three months of age. That's because of HIB vaccine coverage.

\section{TWO MONTHS TO 36 MONTHS}

In this age group the incidence of occult bacteremia, which is a frequent cause of fever of undetermined origin, seems to have decreased over time in developed countries because of vaccine against Haemophilus infuenzae and Streptococcus pneumoniae.

The evaluation of nontoxic-appearing, young, febrile children has been a subject of considerable debate. Of young, nontoxic-appearing children aged 2 to 36 months with temperatures of 39 degrees $\mathrm{C}$ or more and no clear source of infection is identified, approximately $25 \%$ of untreated patients have persistent bacteremia or develop new focal infections, including $3 \%$ to $6 \%$ who develop meningitis and occult meningococcal bacteremia, although rare, has frequent complications, including meningitis in approximately $40 \%$ and death in approximately $4 \% \cdot{ }^{9}$. But in developing countries we do not have enough data to observe these facts. It is believed that Hemophilus influenzae type B and Streptococcus Pneumoniae constitutes probably $95 \%$ to $98 \%$ of all cases of occult bacteremia. Regardless where we see 
children in this country, that's the major pathogen. The common pathogens isolated in these children are Streptococcus pneumoniae, Hemophilus influenzae and Neisseria meningitidis. ${ }^{10}$ The incidence of penicillin resistant pneumococcus has gone up in the last five to six years.

\section{OCCULT BACTERAEMIA}

In the study done by Alpern ER et al the overall rate of occult bacteremia was $1.9 \% \quad(95 \%$ confidence interval [CI]: 1.5-2.3). S pneumoniae accounted for 92 of 111 isolates $(82.9 \%$; 95\% CI: 74.6-89.4) in children with occult bacteremia. ${ }^{11}$. The risk of a child with occult pneumococcal bacteremia later having meningitis is approximately $3 \% .{ }^{12}$ Persistence of bacteremia, depending on the studies, anywhere from $7 \%$ to $50 \%$ and meningitis in $27 \% .{ }^{13}$ Hemophilus influenzae was the commonest cause in the past in developing countries but its incidence has been reduced remarkebly with the introduction of the Hib vaccine. Depending upon the study, from $7 \%$ to $22 \%$, probably about $17 \%$ or $15 \%$ or so are going to be persistently bacteremic 24 to 48 hours later. ${ }^{14}$ Meningitis is going to be seen in about $6 \%$. Longer the bacteria is in the circulation, greater the possibility of having meningitis.

\section{SERIOUS BACTERIAL INFECTION}

A child who appears ill, respiratory rate of equal or more than 60 per minute, chest inddrawing, grunting, cyanosis, wheezing, lethargic, toohot, too cold or distended abdomen may have possible serious bacterial infection. ${ }^{15}$ If any one of these criterias are present then that child is going to be in a high risk for serious bacterial infection. When these clinical criteria are not present we may call low risk clinical criteria, and using this coupled with some laboratory data one can follow-up those children that are lowest risk for serious bacterial infections. In other words, when we look these children, they are relatively happy? If we bring the fever down they smile. Do they try to interact with us? If they try to interact with us, then they are low risk children. Otherwise they are probably falling out of the low risk group and may be at high risk for serious bacterial infection. On physical examination there should be no focal bacterial infection identifiable, other than possibly an otitis media. And lastly, the child should come from a good social situation and can be easily followed up.

\section{LABORATORY INVESTIGATIONS}

When compared with "no work-up," the strategy of "CBC + selective blood culture and treatment" using a white blood cell (WBC) cutoff of 15 x 10(9)/ $\mathrm{L}$ prevents 48 cases of meningitis, saves 86 lifeyears per 100000 patients, and is less costly at the current rate of bacteremia $(1.5 \%) .{ }^{11}$ The other issue is the absolute band count. It's simple; take that percentage of bands in the report e.g. $15 \%$ and multiply it times the total white count. So if we have got a white count of 10,000 and our band count is $15 \%$, then the absolute band count is 1,500 cells. So what most authorities are recommending is that if the absolute band count is above 1,500 then that child might be infected and probably needs to be worked up. If the white count is below 2000 there may be overwhelming sepsis.

A urine analysis should be obtained in these children and should be normal; as defined by less than 5 WBC's per high power field. Or should have a negative gram stain by smear. If If the child has diarrhea there should be less than 5 WBC's per high power field because that correlates with an absence of a bacterial pathogen. If all those criteria plus the previous criteria are met, that child is in the low risk group and that's the child that's going to have that $1 \%$ risk for serious bacterial infection, 
$1 \%$ risk for bacteremia, and less than a percent, less than $0.5 \%$ for meningitis. That child can usually be managed as an out-patient.

The Kernig's and Brudzinski's sign, those classic signs of meningitis, do not become fully developed until the child is about a year to 15 months of age. So a negative Kernig's and Brudzinski's in a child less than 15 months of age, doesn't rule out meningitis. We can make them to look up and down and move their head and if they can they probably don't have meningitis provided there are no other signs involved.. Paracetamol for control of pain and fever and then of course, the all important follow-up in 24 to 48 hours. Bring them back and look them over.If there is history of convulsion and no other specific signs, lumbar puncture should be done and the rsult of CSF should be available withing 30 minutes. This helps to differentiate the first episode of febrile seizure with meningitis.

\section{ALOGORITHM}

Here are the options for children less than 28 days of age - this is very much similar as out lined in the IMCI guidelines developed by WHO for young infant. ${ }^{16}$ Option number one: for a child less than 28 days of age we are recommending hospitalization and a substance evaluation for all children with a fever greater than 100.4F. That's because the pathogens that they are subjected to at this age group are particularly virulent and as we all know, they have a relative immaturity in their immune system. The substance evaluation should include a CBC with differential, the serum glucose , a lumbar puncture which should include a cell count with differential, protein and glucose determination, and a bacterial culture at minimum.

Next algorithm for old children: The first question we are going to ask ourself here is, is this a non- toxic appearing previously healthy child? If the answer is no, if they look sick, they probably have to be admitted in the hospital. And we need to do our complete sepsis work-up and parenteral. That is, either cefotaxime of ceftriaxone empirically. Now, if the child meets this first cut off, or first break point, and the answer is yes, then the next break point is temperature. If we have a temperature that is less than 39C degrees, there really isn't much to do. We don't have to do any diagnostic tests or give antibiotics. Just examine the child and make sure there is nothing that we are missing. Antipyretics should be given. Generally paracetamol is sufficient. The patient should be instructed to return or given an appointment to return in 24 to 48 hours, or sooner if the patient is getting worse or not better. On the other hand, if the temperature is greater than $38 \mathrm{C}$ degrees then we should proceed with some type of an outpatient's work-up and that depends on what the constellation of symptoms are for each child. So in general, if the child is a male and less than six months of age, or a female less than two years of age, a urine culture should be obtained to rule out a urinary tract infection. Stool culture is there is blood or mucus in the stool, or if there's greater than 5 WBC's on stool smear.

If the patient has respiratory symptoms the guidelines therefore emphasise the importance of tachypnoea in the diagnosis of childhood pneumonia, defined according to the usual WHO criteria: In children <2 months: $>60$ breaths/minute ,in children 2-12 months: $>50$ breaths/minute and in children $>12$ months: $>40$ breaths/minute.

The best guide to distinguishing bacterial from viral pneumonia is clinical acumen, and the Guidelines present two well validated clinical observations that should reduce inappropriate antibiotic use in toddlers, while identifying those children who do need antibiotics: in the preschool 
child, if wheeze is present, primary bacterial pneumonia is unlikely. Bacterial pneumonia tends to be associated with pyrexia, dyspnoea, and tachypnoea; bacterial pneumonia should be considered in children up to 3 years of age with a temperature $>38.5^{\circ} \mathrm{C}$ along with chest recession and respiratory rate $>50$ per minute. ${ }^{17}$

The case for performing a chest $x$ ray as part of the investigation of a febrile child with no respiratory signs is dubious. The Guidelines suggest: if clinical signs are present, $x$ ray examination is not necessary to diagnose pneumonia and in children in whom clinical recovery has been satisfactory, repeat $x$ ray examination serves no useful purpose. ${ }^{18}$ Here the advice is simple and to the point: there is no indication for any tests in a child with suspected pneumonia in the community.

Blood culture should also be obtained if the white count is greater than 15,000." And that's because we know that when the white count is greater than 15,000 we have a higher rate of bacteremia. It's one way of being cost effective. Empiric antibiotic therapy again can be linked with the issue of white count and temperature. So that if the white count is greater than 15,000 and the temperature is greater than 39C degrees give the antibiotic.

Some of us advocate initiating empiric antibiotics until we have the results of the 48 or 72 -hour blood culture. It seems that the interval from the time of the blood draw to the time that we can consider them negative has decreased in time over the last few years. That probably has to do with the fact that we have better culture systems than we did in the past. It now appears that with the newer systems they are so accurate that we get a good idea by 48 hours. And if the blood cultures are negative at 48 hours we can stop the antibiotics, and if the child is doing well, consider sending him home. Or treat them longer if they are not doing well yet.

\section{ANTIBIOTICS}

Fever of unknown origin (FUO) is best defined as fever without obvious source on initial clinical examination and then classified into acute (illness of $<$ or $=1$ week's duration) and prolonged ( $>7$ to 10 days' duration). Aetiologically, there is a marked overlap between acute and prolonged FUO, and infections are major players in both. Age, climate, local epidemiology and host factors are the major aetiological factors that should be considered in the choice of definitive tests. Depending on age, serious bacterial infections (including bacteraemia, meningitis and urinary tract infection) occur in 3 to $20 \%$ of cases of acute FUO. Prevention of mortality and sequelae from these infections, particularly bacteraemia and meningitis, is of particular concern in acute FUO. An individualised approach, based on clinical evaluation supplemented with screening and definitive laboratory tests to determine the need for empiric antibiotic therapy and hospitalisation, seems to be the best approach to acute FUO (although this may be less applicable to neonates and infants younger than 90 days, particularly those aged 0 to 7 days). The place of laboratory tests, empiric antibiotic therapy and hospitalisation are important issues that are likely to remain so for some time. ${ }^{19}$ The appropriate antibiotics for a child less than 30 days of age is ampicillin plus gentamicin. The ampicillin/gentamicin should cover most of the pathogens at this age group. Newer regimens include things using like cefotaxime and ampicillin. The common denominator in both of these is the ampicillin component and that's because that component offers coverage for Listeria monocytogenes. Listeria is not covered by the cephalosporins alone. Ceftriaxone is not used in this age group, because it displaces bilirubin from its albumin-binding sites, and so it can lead to kernicterus or jaundice. 
CONCLUSION

There are ample evidences to suggest that investigations and antibiotics are not indicated in children under the age of 36 months if they do not have signs of serious bacterial infection. Surveys also indicate that many physicians do not agree with recommendations for venipuncture and bladder catheterization in nontoxic febrile children, and that many employ watchful waiting rather than empiric antibiotic therapy. Surveys of parents note a preference for less testing and treatment. More aggressive management may be appropriate in febrile infants younger than three months old; however, criteria have been proposed to identify infants older than one month who are at low risk for serious bacterial infection. Because of widespread vaccination against Haemophilus influenzae infection, Streptococcus pneumoniae has become the cause of most cases of bacteremia in western countries. However in developing countires these bacteria are the major cauese of serious bacterial infection and it should be remembered in choosing the antibiotics. The risk of serious bacterial infection is greater in younger children and in those with higher temperatures and white blood cell counts. These variations affect both cost and standard of care. Future studies assessing whether these strategies affect patient outcomes would further elucidate their clinical implication. Pediatric health care providers have a unique opportunity to make an impact on parental understanding of fever and its role in illness. There is poor compliance with published practice guidelines in the management of febrile infants and children among medical professionals. Future studies are needed to evaluate educational interventions and to identify the types of medical care practices for fever.

\section{REFERENCES}

1. Sandy Gove Integrated Management of Childhood IIlness. In Strickland GT(Ed) Hunter's Tropical Medicine and Emerging Infectious Diseases. $8^{\text {th }}$ Ed. WB Saunders Co. 2000.125-140.

2. Russel G. Community acquuired pneumonia, Arch Dis Child 2001; 85: 444-446.

3. Peltola $\mathrm{H}$, Heinonen OP. Frequency of true adverse reactions to measles-mumps-rubella vaccine. A double-blind placebo-controlled trial in twins. Lancet 1986; 1: 939-942

4. Pulliam PN, Attia MW, Cronan KM.C-reactive protein in febrile children 1 to 36 months of age with clinically undetectable serious bacterial infection. Pediatrics 2001 Dec; 108(6): 1275-9

5. Cheng TL, Partridge J C.Effect of bundling and high environmental temperature on neonatal body temperature. Pediatrics 1993 Aug; 92(2): 238-40

6. Luszczak M Evaluation and management of infants and young children with fever. AmFam Physician 2001 Oct 1; 64(7): 1219-26

7. Buckingham SC, McCullers J A, Lujan-Zilbermann J, Knapp KM, Orman KL, English BK. Pneumococcal meningitis in children: relationship of antibiotic resistance to clinical characteristics and outcomes. Pediatr Infect Dis J 2001 Sep; 20(9): 837-843

8. Kamalaratnam CN, Kang G, Kirubakaran C, Rajan DP, Daniel DJ, Mathan MM, Mathan VI.A prospective study of nosocomial enteric pathogen acquisition in hospitalized children in South India. : J Trop Pediatr 2001 Feb; 47(1): 46-9.

9. Kuppermann N.Occult bacteremia in young febrile children. : Pediatr Clin North Am; 1999 Dec; 46(6): 1073-109.

10. Jamuna R, Srinivasan S, Harish BN.Factors predicting occult bacteremia in young children.: Indian J Pediatr. 2000 Oct; 67(10): 709-11

11. Alpem ER, Alessandrini EA, McGowan KL, Bell LM, Shaw KN Serotype prevalence of occult pneumococcal bacteremia. : Pediatrics 2001 Aug; 108(2): E23 
12. Baraff $L J$ Management of fever without source in infants and children. : Ann Emerg Med 2000 Dec; 36(6): 602-14

13. 16. Di Troglia J. Occult bacteremia froma pediatric emergency department. Pediatrics. 2001 Aug; 108(2): 520-1.

14. Greenes DS, Harper MB.Low risk of bacteremia in febrile children with recognizable viral syndromes. : Pediatr Infect DisJ 1999 Mar; 18(3): 258-61.

15. Brady JP, Awan FB, Wafula EM, Onyango FE. Recognition of illness in very young infants by inexperienced health workers.Ann Trop Paediatr. 1993; 13(4): 401-7.

16. Gupta R, Sachdev HP, Shah D.Evaluation of the WHO/UNICEF algorithm for integrated management of childhood illness between the ages of one week to two months. I ndian Pediatr. 2000 Apr; 37(4): 383-90.

17. Cherian T, J ohn TJ, Simoes E, et al. Evaluation of simple clinical signs for the diagnosis of acute lower respiratory tract infection. Lancet 1988; 2: $125-128$

18. 19. 19. Swingler GH, Hussey GD, Zwarenstein $M$. Randomised controlled trial of clinical outcome after chest radiography in ambulatory acute lowerrespiratory infection in children. Lancet 1998; 351: 404-408

19. Akpede GO, Akenzua GI Aetiology and management of children with acute fever of unknown origin. PaediatrDrugs 2001; 3(3): 169-93.

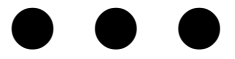

\section{Notice for Fund Raising}

The Journal of Nepal Medical Association (JNMA) is consolidating all its efforts in upgrading the quality of the Journal that could subsequently lead to international recognition and indexing. The necessary changes in editorial policy have already come into effect and activities (e.g., peer reviewing, copy editing, statistical review etc) pertaining to it have been initiated. However, the Journal is currently short in funds to effectively conduct these activities. Hence, fund raising has become inevitable but as to how best funds could be raised and mobilized is still a question. Among those thought of are creating a revolving fund and/or acquiring a physical facility and renting them out so that the incurred interest and/or rent could be utilized to support the activities.

In this regard the Journal looks forward to the opinions of its valued readers. Comments and queries may be forwarded to the Chief Editor of Journal. 